\title{
Left handedness in an identical twin discordant to his co-twin for handedness and schizophrenia, with neurological and psychometric evidence of left hemisphere damage
}

\author{
Malcolm P.I. Weller
}

Friern Hospital, Friern Barnet Road, London N11 3BP, UK.

\begin{abstract}
Summary: A left handed, monozygotic, male twin developed schizophrenia, whilst his right handed brother was free of psychopathology. There was no family history of mental illness or left handedness. The affected twin had left side motor weakness and an EEG showed scattered irregularities, particularly on the left. Psychometry indicated left sided tempero-parietal dysfunction. The relationship between left temporal lobe damage and schizophrenia is considered.
\end{abstract}

\section{Introduction}

Damage to the left hemisphere, and particularly the left temporal lobe is associated with schizophrenia or schizophreniform psychosis. ${ }^{1-3}$ Left temporal lobe epilepsy has such an association after an average period of 14 years. ${ }^{3-5}$ Similarly penetrating gun shot wounds to the left temporal lobe are associated with psychotic sequelae. ${ }^{5,6}$ Those developing schizophreniform psychoses in Slater, Beard and Glithero's series ${ }^{4}$ did not have a family history of schizophrenia, drawing a distinction between familial and sporadic cases of schizophrenia which can complicate genetic studies.

The left temporal horn area, was smaller in the postmortem brains of 41 schizophrenic patients ${ }^{7}$ and there are suggestions of a neurodevelopment deficit. ${ }^{2.8 .9}$

There is high incidence of infant deaths and congenital malformations in the offspring of schizophrenic mothers and there are more birth complications in children born in a group at high risk of schizophrenia. A larger proportion of schizophrenic patients than controls was small for gestational age at birth and significantly lower in birth weight than their siblings. In those schizophrenic patients with little genetic loading, the evidence of birth injury was greater than with those who had a strong family history of schizophrenia. $^{1-3.9,10}$

Marked anoxia at birth in one of two twins is often associated with schizophrenia in that twin in a pair discordant for the disease. ${ }^{.1}$

Correspondence: M.P.I. Weller, M.A., F.R.C. Psych., F.B.Ps.S

Accepted: 26 July 1989
Widening of the lateral ventricles has been frequently documented in schizophrenia and the degree of widening distinguishes between affected and non-affected identical (monozygotic) twins. ${ }^{10}$

Boklage $^{12}$ analysed the twin series selected for the presence of schizophrenia of Gottesman and Shields, and Slater, and showed that in monozygotic twins who are concordant for handedness and dextral the concordance for schizophrenia is very high $(93 \%)$ but in twin pairs discordant for handedness the concordance for schizophrenia falls to $23 \%$, the course of the disease being more benign in this group. A case is described that conforms to this latter pattern.

\section{Case report}

A male patient born in 1939 first came to my attention in March 1981 with a diagnosis of probable schizophrenia. He had been extremely self neglectful, was emotionally flat, with poor rapport, but there were no unequivocal psychotic symptoms. He had begun to notice a change in his personality and his body in 1975 . This progressed gradually until 1978, when he had a 'breakdown' and was assessed in the outpatient department but no diagnosis was made. Subsequently he felt forces coming into him from the television and briefly started to hear voices.

In 1978 he complained that the whole of his psychic power was going out of his mind. He claimed that until that time he was a hard working conscientious, happy-go-lucky person but had gradually lost interest in work and developed 
'transfiguration, i.e. splitting of personality'. He felt that his brain cells were dying insidiously, which despite great effort he was unable to resist. In February 1981 he began to exhibit thought block, to misuse words frequently, and to be very difficult to follow, for example, when asked about his thought block he said 'There is no sort of egoism or anything about it'. He was admitted to hospital in February and again in July because of social deterioration and was occasionally unintelligible through thought disorder. There were some memory deficits on clinical testing.

When interviewed in March 1988 he complained; 'I'm mindless, just air, I have no thoughts, no emotions or anything. I am living but I am not aware of it.' In October 1988 he voiced a similar complaint; 'I'm just coping like a puppet at the moment, my mind is still a blank, I have no feeling or emotions anymore, just a ghostly effect.'

He was treated with neuroleptics, which abolished his thought disorder and improved his mood, and is currently receiving fluphenazine decanoate $25 \mathrm{mg}$ three times weekly. He is employed in a resettlement scheme and is learning typing but complains of poor bimanual coordination and weakness in his right hand.

He was a second born identical twin, delivered half an hour after his brother. His co-twin became a nurse after his A level success, and never had any psychiatric problems, nor was there any other family history of mental illness, but he died last year of cancer in Canada. The patient was less intelligent than his twin brother, attending an inferior school from the age of 13 and leaving at 15 without any certificates. Unlike his brother, and any other known family member, he was left handed.

On examination there was a weakness in the extensor and flexor compartments of the right arm, forearm and intrinsic muscles of the hand. The sternomastoid muscle was also weak on the right, but there was equal power in the deltoids, and in the leg muscles.

The diameter of the right forearm was $9.25 \mathrm{~cm}$ at the point of maximal muscle bulk, $5 \mathrm{~cm}$ from the olecranon, and the left $10 \mathrm{~cm}$, and the diameter of the right biceps at the point of maximal muscle bulk, $10.6 \mathrm{~cm}$ from the olecranon, was $7 \mathrm{~cm}$ and on the left $10.8 \mathrm{~cm}$. The quadriceps were equal in bulk on both sides. The biceps reflex was brisk on the right, there were absent abdominal reflexes on the right, which were present on the left. The plantar response was equivocal on the right, with fanning of the toes.

Psychometry revealed some degree of dyscalculia and 'quite severe nominal dysphasia', both consistent with organic damage to the dominant tempero-parietal region.

An EEG showed scattered delta and theta waves with a left sided preponderance. A plain CT scan failed to reveal any abnormality.

\section{Discussion}

The chronicity and phenomena, particularly formal thought disorder, places the condition centrally in the category of schizophrenia. ${ }^{3}$ However, the organic aspects challenge this diagnosis. I have argued elsewhere that such functional and organic distinctions are increasingly untenable. ${ }^{3}$

The neurological findings are indicative of a left sided upper motor neurone lesion, suggesting the possibility of the left handedness being acquired. The EEG would support the probability of wide spread disturbance, but still concentrated in the left cerebral hemisphere. The psychometry confirms this impression and localizes the cognitive defects to the left tempero-parietal area.

The schizophrenia is plausibly related to left hemisphere brain damage that probably occurred at the time of birth, and conforms to the series of monozygotic twins discordant for schizophrenia, analysed by Boklage. ${ }^{12}$ The clinical picture was dominated by changes in the sense of self, volition and relationship with the external world, with impoverishment in emotional life and thought, phenomenological features which are associated with neurological findings ${ }^{13,14}$ and a poor prognosis. ${ }^{15}$ Nevertheless, on treatment the patient copes in sheltered employment and is well liked, rational and coherent, his disease following a relatively benign, if chronic, course, as described by Boklage $^{12}$ in left handed affected twins in twin pairs discordant for schizophrenia.

\section{Acknowledgement}

I thank Mrs G. Dunkley for psychometry and Friern Hospital for library assistance.

\section{References}

1. Flor-Henry, P. Cerebral Basis of Psychopathology. John Wright, Boston, Bristol and London, 1983.

2. Murray, R.M. \& Lewis, S.W. Is schizophrenia a neurodevelopmental disorder. (leading article) $\mathrm{Br} \mathrm{Med} \mathrm{J}$ 1987, 295: $681-682$.

3. Weller, M.P.I. Some problems in the diagnosis of schizophrenia and the concept of clear consciousness. Stevens, $\mathbf{R}$. (ed.) Aspects of Consciousness. Academic Press, London, New York, Tokyo etc., 1984, pp. 117-166. 
4. Slater, E., Beard, A.W. \& Glithero, E. The schizophrenia like psychoses of epilepsy. Br J Psychiatry 1963, 95: 109-150.

5. Weller, M.P.I. The sequelae of head injury and the postconcussion syndrome. In: Granville-Grossman, K. (ed.) Advances in Clinical Psychiatry, vol. 5. Churchill Livingstone, Edinburgh, London etc, 1985.

6. Lishman, W.A. Brain damage in relation to psychiatric disability after head injury. $B r J$ Psychiatry 1968, 114: 373-410.

7. Brown, R., Colter, N., Corsellis, J.A.N. et al. Postmortem evidence of structural brain changes in schizophrenia. Arch Gen Psychiatry 1986, 43: 36-42.

8. Weller, M.P.I. Frontiers of psychiatry. In: Weller, M.P.I. (ed.) The Scientific Basis of Psychiatry. Bailliere Tindall, London 1983, new edition in preparation, pp. 1-33.

9. Weinberger, D.R. Implications of normal brain development for the pathogenesis of schizophrenia. Arch Gen Psychiatry 1987, 44: 660-669.

10. Reveley, A.M., Reveley, M.A. \& Murray, R.M. Cerebral ventricular enlargement in non-genetic schizophrenia: A controlled twin study. Br J Psychiatry 1984, 144: 89-93.
11. Pollin, W. \& Stabenau, J.R. Biological, psychological and historical differences in a series of monozygotic twins discordant for schizophrenia. In: Rosenthal, D. \& Kety, S.S. (eds) The Transmission of Schizophrenia. Pergamon, Oxford 1968, pp. 317-332.

12. Boklage, C.E. Schizophrenia, brain asymmetry development and twinning: cellular relationship with aetiological and possibly prognostic implications. Biol Psychiatry 1977, 12: 19-35.

13. Gross, G. \& Huber, G. Report to third Biannual Workshop on Schizophrenia, Schladming, Austria, 1986.

14. Kety, S.S. The syndrome of schizophrenia: unresolved questions and opportunities for research. Br J Psychiatry 1980, 136: $421-436$.

15. Vaillant, G.E. Prospective prediction of schizophrenic remission. Arch Gen Psychiatry 1964, 11: 509-518. 